\title{
DESMONTANDO CLICHÉS O LA EVOLUCIÓN DE LOS MODELOS DE FEMINIDAD Y MASCULINIDAD EN LOS ESCENARIOS
}

\author{
DEBUNKING CLICHÉS OR THE EVOLUTION OF MODELS OF \\ WOMANHOOD AND MANHOOD ON STAGE
}

\author{
Maribel MARTÍNEZ LÓPEZ \\ Universidad de La Rioja \\ maribel.martinez@unirioja.es \\ orcid 0000-0003-4466-1962
}

\section{Resumen}

El teatro puede ser entendido como un laboratorio de estudio de las inquietudes sociales de cada época y desde él se reflejan y se constatan unas realidades que representan a la sociedad en la cual los textos nacen. Pero a la vez, las obras dramáticas, desde el texto, pero especialmente desde su puesta en escena, ayudan a entender los conflictos que presentan y a avanzar en el camino que se quiere recorrer para su solución. En este sentido, en el teatro español actual descubrimos la presencia y la transformación de las identidades de género. Desde el acercamiento a algunos textos de autores españoles, descubriremos cómo los escenarios muestran los modelos de feminidad y de masculinidad vigentes, así como los pasos hacia la normalización social de las diferentes identidades sexuales. Un estudio comparado de las obras permite obtener un diagnóstico certero de la evolución de modelos en la sociedad de principios del siglo XXI.

Palabras clave: teatro español actual, identidad de género, feminidad y masculinidad, conflictos sociales.

\begin{abstract}
Theater plays can be understood as a laboratory of study of the social concerns belonging to each period and from it, some realities are both reflected and verified, which represent the society in which the texts are born. But at the same time, the dramatic works, from the very same text but especially from its staging, help understand the
\end{abstract}


conflicts they present and advance to carry on down the path that is necessary to go for its solution. In this sense, in the current Spanish theater, we discover the presence and the transformation of gender identities. From the approach to some texts by Spanish authors, we will discover how these stages show the female portray model and masculinity in force, as well as the steps towards the social normalization of the different sexual identities. A comparative study of the plays allows us to compile an accurate diagnosis of the models in society at the beginning of the 21st century.

Keywords: current spanish theater, gender identity, female portray model and masculinity, social conflicts. 


\section{TEATRO: PULSIONES SOCIALES}

Cuando estudiamos aspectos relacionados con la presencia y el tratamiento de cuestiones de género en el teatro español contemporáneo nos encontramos con un amplio muestrario de todas las fotografías sociales que conforman nuestro día a día y sobre las que se construye nuestra ideología, nuestros comportamientos y nuestra educación sentimental. En este sentido, el tratamiento de cuestiones de identidad de género está en relación con el planteamiento de las identidades así como con las conductas sociales de cualquier grupo. Por ello, la reflexión sobre las nuevas feminidades y las nuevas masculinidades no puede abstraerse de aspectos como las relaciones de pareja, la asunción de roles en la familia, la educación de los hijos, las relaciones interpersonales y, en este ámbito, el uso de las redes como forma de interacción social, así como otros múltiples factores que constituyen nuestra cotidianidad y se plantean en los textos teatrales.

El teatro actual refleja la evolución tanto en las identidades como en las normas y en las características de género que presentan los modelos actuales de masculinidad y feminidad en obras como Hojas de algún calendario ${ }^{1}$ y Whatsapp ${ }^{2}$, ambas de Juana Escabias, que escenifican las relaciones interpersonales a través de las redes; o trata problemas como el ciberacoso en textos como Mr Hitchcock vs Carolinal6, de Paco Bezerra, que presenta la extorsión de un hombre adulto a una chica adolescente. También en Etiopía, de Yolanda Dorado, se trata otro tema como el de la anorexia y el intento de suicidio de una adolescente cuya madre, profesional de éxito, trabaja tanto que no tiene tiempo para ver los problemas de su hija, planteando así la situación de esos

1. Hojas de algún calendario presenta a Raúl (19 años) y Rita (17) en un cibercafé. Él acude allí con el objetivo de conocer a gente. Ella va para chatear y escribirse con Capitán Lunar (que es Raúl). Cuando él le confiesa su identidad, ella se enfada porque prefiere que la relación entre ellos sea a través de la pantalla, donde todo es más fácil e idílico.

2. En Whatsapp JuanaEscabias presenta a una adolescente de 16 años que el día de su cumpleaños prefiere no salir a celebrarlo con sus amigas y chatear por whatsapp con su novio solo porque él, que no la trata muy bien, siente celos de que se divierta con ellas. 
hijos que tienen la vida que los padres han soñado para ellos, pero al mismo tiempo del precio que todos ellos, padres e hijos, pagan por alcanzarla ${ }^{3}$.

En lo relativo a los paradigmas de género, y dentro de ellos, a aspectos todavía controvertidos para la sociedad, como la identidad sexual o la intolerancia en las relaciones amorosas «no ortodoxas» en las que los roles se invierten, el texto dramático, por su concepción dialógica y su efecto espejo, es una importante herramienta didáctica y de lucha. En el texto y sobre el escenario se presentan los modelos y las formas de conducta que son producto, por un lado, de los cambios en la sociedad, pero al mismo tiempo aceleran el proceso incidiendo en los cambios de mentalidad del espectador o de la espectadora, en sus gustos y en sus formas de concebir el mundo y moverse por él.

\section{PRESENCIA Y TRATAMIENTO DE IDENTIDADES DE GÉNERO EN EL TEATRO. PASOS HACIA LA NORMALIZACIÓN SOCIAL DE LA HOMOSEXUALIDAD}

En la década de los 90, en España se produjo cierta visibilidad de la literatura homosexual tanto en lo referente al reconocimiento de los autores o a la presencia temática de esta realidad, como al apoyo de editoriales y premios a las publicaciones. Antes de esa época, la tendencia era o bien ignorar el tema de la homosexualidad o bien representarlo de forma negativa. En el campo teatral uno de los dramaturgos que trataron la temática gay fue Rafael Mendizábal, autor con grandes éxitos de taquilla en la década de los 80. En 1994 estrenó Feliz cumpleaños, señor ministro, texto que presentaba la homosexualidad y la transexualidad. Y en 2003 se estrenó su obra más importante sobre la homosexualidad: Madre amantísima, en la que ofrece una reflexión desde presupuestos ideológicos conservadores y burgueses sobre el conflicto que crea la homosexualidad para la sociedad.

Nos referiremosaquí a textos y espectáculos escritos y estrenados en España entre 2012 y 2017 que cuestionan los esquemas de roles, normas y características de género, en los que se presenta de manera natural o conflictiva la homosexualidad con el objeto de ayudar a su normalización en nuestra sociedad.

Comenzamos citando Mis padres no lo saben, una obra de teatro dirigida por Javier Corral en el año 2012 que, basada en el libro homónimo de Marce Rodríguez y Mariola Cubells, presenta a través de doce monólogos el difícil conflicto de reconocer la homosexualidad ante la familia y en el entorno social.

3. Hojas de algún calendario, Mr. Hitchcock vs Carolina16 y Etiopía están incluidas en la colección El tamaño no importa. Textos breves de aquí y de ahora, editada por la AAT. 
En ella se suben al escenario testimonios reales para mostrar fotografías de vidas de personas de carne y hueso que sufren porque su condición sexual les hace la existencia un poco más difícil que a otros ${ }^{4}$. Las historias reflejan que queda todavía mucho por hacer para la normalización de las diferentes identidades sexuales, cuya aceptación es necesaria para una transformación real de los roles de género.

Frente a este acercamiento a un conflicto real, La Vida es Bell@, espectáculo de Carlos De Matteis ${ }^{5}$, plantea una historia sobre el amor, la vida y la muerte en la cual se profundiza en la esencia del ser humano y sus sentimientos más profundos, y en la que el conflicto no reside en la identidad sexual. Basada en la obra teatral Los días contados, de Franklin Rodríguez, la puesta en escena de Carlos De Matteis presenta el mismo diálogo interpretado por tres parejas diferentes, una lesbiana, una gay y otra heterosexual, para mostrar que los conflictos del amor o del desamor y las relaciones de pareja no residen en la inclinación sexual de sus componentes, sino en sus identidades personales y en las relaciones entre personas, independientemente de sus sentimientos de género.

Por último, Cállate y bésame, también de Carlos De Matteis, plantea los conflictos de pareja entre Lola y Renata, cuya turbulenta relación muestra que no pueden estar juntas, pero tampoco separadas. Sus problemas de pareja no están vinculados con su orientación sexual, sino con sus relaciones interpersonales. Cállate y Bésamees una divertida comedia romántica que habla del amor, de los enredos en las relaciones de pareja y de la fidelidad, de cuántas maneras hay de ser infiel, y si debe perdonarse una infidelidad o si existe un manual para ser el perfecto amante. Se trata de un texto dramático que puede ser encarnado por una pareja gay o una heterosexual, defendiendo, desde la afirmación de rasgos individuales y no de paradigmas sociales, la lucha por la normalización y la libertad de identidad sexual, y la ruptura de características de género, así como de sus roles y normas.

\section{MODELOS DE FEMINIDAD Y MASCULINIDAD: AVANCES Y RETOS ${ }^{6}$}

Tras estos tres textos, reflejo real de un clima social y del deseo de avanzar en la lucha por la igualdad de género, vamos a centrarnos en el modo en el que el

4. Podemos encontrar información sobre este montaje en <http://mispadresnolosaben. blogspot.com.es/>.

5. Podemos encontrar información sobre este autor y director teatral argentino, y sus textos y montajes en <http://www.alternativateatral.com/persona39338-carlos-de-matteis>.

6. Los textos a los que me referiré en este apartado no están aún publicados aunque sí estrenados -excepto uno-. A través de la base de datos www.contextoteatral.es se accede 
teatro español contemporáneo ayuda a entender y a construir las feminidades y masculinidades, nuevas y tradicionales, en el siglo XXI.

En los textos dramáticos encontramos ya de forma habitual, incluso mayoritaria, protagonistas femeninas fuertes, racionales, emancipadas, mujeres activas y muy competentes personal y profesionalmente, junto a hombres que son ahora mucho más sensibles y espirituales, sin perder por esto ni ellas ni ellos otros rasgos definitorios de su género. Entre ambos sexos se establece, como vemos en los escenarios, una relación igualitaria, alternante, donde los valores, actitudes y características de ambos consiguen un equilibrio y se fortalecen mediante el intercambio en una fructífera relación de camaradería y amistad que no excluye una posible atracción física. Comportamientos y actitudes que antes parecían destinados a los varones, ahora se hacen extensibles a las mujeres y, en menos casos, se produce el fenómeno a la inversa ${ }^{7}$.

No obstante, la igualdad no se ha conseguido, pese a que sea indiscutible que se ha producido un cambio en los modelos de feminidad y masculinidad actuales respecto al siglo XX. Los datos económicos y laborales más actuales muestran que los antiguos roles de género todavía no han sido desterrados del mundo del trabajo y que la maternidad no ha dejado de ser aún uno de los principales motivos de abandono del mercado laboral. En estos años de crisis las estadísticas han reflejado una y otra vez que los hombres siguen acaparando los nuevos empleos, frente a la calidad del trabajo femenino cada vez más deteriorada, o que el porcentaje de hombres que piden excedencias para el cuidado de los hijos es casi inexistente. Todo ello supone una enorme presión para la mujer, como plantea en tono de comedia Mercé Sarriás Forner en Hazme una perdida (2014). Esta obra es un alegato en contra del concepto de superwoman, parejo a la emancipación laboral de la mujer, que se localiza y se dota de significados desde la década de los 90 del siglo XX y que cobra matices negativos en el siglo $\mathrm{XXI}^{8}$.

a una breve sinopsis de cada obra, además de que se facilita el poder contactar con los autores. En mi caso he tenido acceso a los textos gracias precisamente a la amabilidad de los dramaturgos que me los proporcionaron.

7. Ver «Algo se consigue», de Lourdes Ortiz, donde la autora reflexiona sobre ello a partir de varios ejemplos de populares series americanas de televisión.

8. Antes de que se conceptualizara ese rol, la historia y la literatura ofrecen muchos ejemplos de mujeres que han tenido que luchar para sobrevivir y para sacar a sus familias adelante, ocupando todo su tiempo en el trabajo. Así, por ejemplo, Alfredo Sanzol dedica su obra Delicadas a su abuela y las hermanas de esta. Delicadas es un título irónico porque trata de mujeres a las que no les dejaron serlo, pues les tocó vivir la guerra y la posguerra y eso les hizo ser fuertes, trabajando duramente para sacar a sus familias adelante. Fuera de la mirada social negativamente evaluadora del triunfo profesional de la mujer y el éxito de 
Hazme una perdida es una comedia en clave de musical, cargada de ironía, que cuenta las aventuras y desventuras de una mujer arquitecta que, intentando sobrevivir al trabajo y la familia, se despierta un día triplicada para poder sobrellevar la peor semana de su vida, en la que confluyen la ausencia de un marido fotógrafo en viaje laboral, el mal ambiente en el trabajo donde nadie entiende que haya pedido jornada reducida, y el cuidado de sus dos hijas pequeñas. Según indica la autora, la obra nace de un encargo de tres actrices que querían explicar su situación después del nacimiento de sus hijos, la dificultad de llevar una vida normal, sin agotamiento, ni descontrol, en un mundo que no está pensado para que la maternidad y la paternidad se vivan de manera relajada, y en el que las mujeres se han llevado la peor parte en su deseo de conciliar el cuidado de los hijos pequeños con la persecución de sus otros sueños.

Y yo que siempre pude con todo, porque me creí lo de la superwoman y pensé que realmente podía criar hijos, trabajar, realizarme y viajar y depilarme, todo al cien por cien, peté. Peté totalmente. Y en la explosión salí convertida en tres. Me tripliqué. Eso sí, mi vida se fue al carajo igual. (2-3)

A lo largo de quince escenas, tres actrices, que representan a una misma protagonista y a la vez encarnan todos los personajes de la obra, reproducen momentos cotidianos reconocibles para la mayoría de los espectadores: desde el ajetreo en los desayunos cualquier día laboral hasta la dependencia de niños y madres del ibuprofeno infantil como solución para casi todo; la lucha contra los piojos en el momento más intempestivo; la inoportuna llamada del colegio en mitad de una importante reunión de trabajo; la frecuencia y facilidad del marido para realizar sus viajes por trabajo y sus negativas consecuencias para la mujer, permanente e injustamente recriminada y ninguneada por el jefe, incluso cuando se le reconoce su alta cualificación y competencia profesional; la espera diaria para acostar a los hijos y seguir trabajando un poquito más; la necesidad de abuelas canguro para cumplir las exigencias del trabajo... Y, en definitiva, las dificultades para las mujeres de armonizar la vida laboral con la familiar y la casi imposibilidad de conciliar el éxito profesional con la satisfacción maternal para la mayoría:

Es mentira, pero en el trabajo conviene no decir nunca que vas a hacer algo relacionado con el hecho de que eres madre. Es muchísimo mejor decir que eres tú la que tienes la gripe, que confesar que tu hija está enferma y tienes que cuidarla. Así se preocupan por tu salud y te consideran una profesional cualificada con gripe, no una madre abnegada y flojeras que prefiere quedarse a sacarle los mocos a su hija que ir a trabajar. (23)

la conciliación familiar, que responde a ese rol de superwoman, no existe la satisfacción o la frustración que el intentar serlo lleva aparejado. 
La conclusión de la obra es el despido de la protagonista, y que se siente sola y con ganas de abandonar, pero no lo hará, se levantará de la caída y se reinventará para luchar hasta vencer, por ella y por sus hijas.

La obra de Mercé Sarriás muestra el nuevo modelo de familia, en el cual la mujer, ahora liberada de su subordinación al marido, trabaja, triunfa y es independiente económicamente. Sin embargo, sabemos que a pesar de todo ello es, con excepciones, el modelo que menos ha cambiado en las últimas décadas, pues la mayor parte de las obligaciones y responsabilidades domésticas siguen recayendo sobre la mujer, y porque el conflicto de la conciliación laboral y familiar sigue siendo una cuestión casi exclusivamente femenina.

En la misma línea nos sitúa la obra Femenino singular, espectáculo coral de Inconstantes Teatro (2015) escrito por sus propios intérpretes: cuatro actrices y un actor. La obra, que escenifica las dificultades cotidianas de las cuatro mujeres, es una comedia sobre la vida que pretende reflexionar sobre las mujeres hoy, desde sí mismas, con los hombres como telón de fondo. Transcurre durante una noche en la que ellas se han liberado de sus responsabilidades familiares y las han delegado momentáneamente en sus parejas, exparejas, abuelos o hermanos, con la precaución de haberles dejado todo preparado y con las instrucciones bien detalladas. Las mujeres han decidido hacer un encuentro entre viejas amigas, con la peculiaridad de que este se va a realizar en un teatro. Allí resulta ser espectador inesperado un técnico de sonido que, de alguna manera, comparte el recorrido de las cuatro mujeres, un tipo que las observa mientras ellas cuentan sus partos, sus relaciones, sus separaciones, sus terapias de pareja, su felicidad, sus infidelidades, sus sueños y sus ilusiones rotas, y que parece esperar pacientemente su turno para contar también su historia9.

Muy interesante es el texto Cama, de Pilar G. Almansa $(2015)^{10}$, una obra cargada de resonancias líricas que presenta la historia de una pareja desde sus primeras citas hasta su divorcio, con custodia compartida del hijo tenido en común. Como señala la autora, su objetivo es explorar los diferentes estadios emocionales dentro de la relación de una pareja de hoy en día que, sin quererlo, reproduce la dinámica de una pareja tradicional, pasando del apasionado enamoramiento inicial al sentimiento de decepción final. Se muestra, desde la perspectiva de las implicaciones que el feminismo tiene actualmente en las relaciones amorosas, el paso de una relación sin compromisos a la adquisición de las obligaciones dentro de la organización cotidiana de una familia con

9. Información sobre este montaje en <http://joomlal.inconstantes.com/index. php?option=com_content\&view=article\&id $=51 \&$ Itemid $=81>$.

10. En 2016 la obra recibió el primer premio en el III Certamen de Nuevos Dramaturgos Lanau Escénica. 
hijos, en la cual los dos miembros de la pareja trabajan. Pilar G. Almansa logra presentar de manera poética a la vez que totalmente realista cómo se ocultan los micromachismos en relaciones de aparente igualdad de género:

ELLA.- ¿Estará ya la lavadora?

ÉL.- ¿No tenías que ponerla tú?

ELLA.- ¿No quedamos en que yo bajaba a comprar lo de la pasta mientras tú ponías la lavadora?

ÉL.- (Bailando.) ¿No quedamos en que yo haría que te sintieras viva?

ELLA.- (Sin bailar.) Necesitaba esa falda para mañana, joder...

ÉL.- $i$ Te acuerdas de que en la hoja de ruta, yo me encargaba del paisaje? ¿De que nunca habría nubes, porque no te gustan los cumulonimbos?

ELLA.- Si la pongo ahora, igual le da tiempo...

ÉL.- ¿Te acuerdas de la oxitocina, de todas las hojas que nunca han caído de ninguno de los árboles que simplemente hemos esbozado? ¿Te acuerdas de tus cenizas y las mías?

ELLA.-Ahora no...

EL.- ¿Cuánto tiempo hace que no te limpias la cerilla de los oídos? ¿Hay alguna pista que me indique cómo se encuentran tus sinapsis? ¿Has visto lo simpáticos que se ponen mis bíceps cuando te huelen? ¿Apagas tus los terremotos internacionales o los apago yo? (pausa.) ¿Ya no quieres acordarte de lo que va a suceder?

Ella.- Lo que va a suceder es que como no consiga mañana ese trabajo, no podremos seguir pagando...

Pausa. Suena el llanto de un bebé.

ÉL.- ¿Te acuerdas de que siempre me querrás? ¿De que hace mil segundos solo uno? ¿De pasta, miedo, estrellas, aguarrás?

Ella.- Desde hace dos segundos, solo uno, te quiero, pero ya no puedo más. (25)

Si en Cama, Hazme una perdida y Femenino singular las protagonistas son las mujeres que encarnan el nuevo modelo de feminidad predominante tras el que se dibuja el paradigma de masculinidad, en otras obras encontramos planteamientos desde protagonistas masculinos, con el resultado del cuestionamiento de los rasgos psicológicos y las normas de género atribuidas tradicionalmente al hombre y que todavía hoy es necesario combatir.

El dramaturgo y actor Alejandro Butrón en Ser un hombre (2017) plantea una reflexión, en clave de humor negro, sobre el concepto de virilidad y sobre todos aquellos supuestos que se adhieren al género masculino desde la infancia, y también, especialmente, sobre la educación y el machismo, así como sobre las críticas antifeministas enunciadas por parte de un sector que se escuda en creer en la igualdad de género y no en feminismos y del que salen en ocasiones ideas sobre el hembrismo o las feminazis. La obra relata la relación de Pepe con su hijo Jorge, que se encuentra en plena pubertad, y del que espera que sea futbolista 
profesional y que se comporte como «un verdadero hombre», siguiendo el mismo esquema en el que Pepe fue educado por su padre y teniendo en cuenta también el ejemplo que ve en casa. Pepe, que perdió su virginidad obligado por su padre en un prostíbulo, se reafirma constantemente como macho. Está dispuesto a enderezar cuanto antes el camino de su hijo, cuya masculinidad es puesta en duda por los amigos de Pepe, como ya le sucediera a él mismo de adolescente con esos mismos amigos a raíz de una anécdota ambigua. En una escena que presenta un flashback de Pepe con quince años, la acotación resume la acción: «Pepe y Luis forcejean y se revuelcan en el suelo, riendo. Finalmente, queda uno sobre el otro. Se miran. Dejan de reír. Se besan. Al cabo de unos segundos, Luis, agitado, se separa de Pepe y se marcha. Pepe queda solo, turbado» (38).

Junto a Pepe, de manera sumisa, aparece María, con la que se casó apresuradamente y cuando apenas se conocían, porque ella se quedó embarazada. Y también de soslayo está el personaje de Silvia, la hija de seis años a la que se educa de manera diferente a Jorge, y con la cual el padre mantiene una canónica conversación sobre la malignidad perpetuada de la mujer desde el pecado de Eva y la manzana. El texto recorre el pensamiento del protagonista para cuestionar qué hace a Pepe pensar de la forma en que lo hace. Jorge, el hijo, se niega a seguir el modelo del padre y se muestra orgulloso de no parecerse a él. Pero tanto Pepe como Jorge son víctimas de un modelo de masculinidad que les asfixia. La obra, en esta concepción de la literatura como espejo de las pulsiones sociales, se escribe desde la emergencia de valores igualitarios que exigen la ruptura de moldes y patrones discriminatorios heredados y la creación de alternativas más acordes con la sociedad actual.

Un segundo ejemplo de lucha por el avance en los modelos de masculinidad trata la presencia todavía hoy de roles machistas encarnados por un personaje tan idealizado como nuestro famoso don Juan Tenorio, que Maykol Hernández reinventa en Desmontando a don Juan (2011) con el objetivo de criticar su ultrajante comportamiento hacia la mujer. La obra presenta al don Juan Tenorio de Tirso de Molina enfrentado en un juicio con el don Juan Tenorio de José Zorrilla. El primero (condenado al infierno en la obra del siglo XVII) decide denunciar a la Justicia Divina por considerar un fraude la sentencia a favor del segundo (cuya alma se salva gracias al amor de doña Inés en la obra del siglo XIX), argumentando que ambos merecen el mismo castigo tras haber llevado la misma vida disoluta. Así pues, ambos personajes, acompañados de sus respectivas enamoradas doña Ana y doña Inés, se ven las caras en un nuevo juicio en el que se rechaza la violencia machista y se desmonta el romántico 
mito del donjuanismo, contra el que argumenta vehementemente la protagonista femenina de la obra de Tirso:

Si perdonamos su conducta simplemente por haberse enamorado de vos o por pedir disculpas justo antes de morir, estamos abriendo una puerta para que todo aquel que decida burlar, ultrajar, o incluso golpear a una mujer, pueda ser absuelto ante este tribunal y rehuir así el castigo que se merece.(23)

[...] ni amando ni sin amor, ningún agravio, violación o agresión debe quedar impune.(24)

En esta parodia, el Divino Juez dicta sentencia a favor de los desenlaces ya elegidos por los autores de ambas obras, si bien concluye que

[...] ambos destinos son inamovibles ya que [...] son personajes que pertenecen al universo literario [...] No obstante, sirva esta farsa para que todos los presentes condenemos el comportamiento de los donjuanes de carne y hueso que solo tratan de probar su virilidad y atractivo.(28)

\section{MUJERES FUERTES / HOMBRES SENSIBLES}

Otro mito se desmonta en Nueve mujeres infieles, obra de Juana Escabias (2013) que propone una revisión de la infidelidad femenina desde una perspectiva que huye de toda crítica moralista. Las protagonistas, insatisfechas con sus relaciones de pareja, buscan el amor en otros hombres como escape previo a poner fin al lastre de sus vidas e iniciar una existencia nueva ${ }^{11}$. Hasta ahora el hombre era el personaje infiel y la esposa tenía que resignarse ante una situación aceptada por la sociedad. Pero en esta obra la mujer es un personaje dinámico y seguro que engaña a su pareja con otros hombres para sentirse liberada de toda opresión o infelicidad. Nueve mujeres infieles está compuesta por trece escenas independientes, algunas relacionadas entre sí, que abordan el tema de la infidelidad femenina desde perspectivas unas veces cómicas y otras dramáticas y crueles. Así, nos encontramos con la esposa que se acuesta con el hermano de su marido; con la que, siendo ella la infiel, echa a su marido de casa y se queda con todo (bienes materiales, pensión y custodia de los niños),

11. Juan Escabias planteó este tema igualmente en su libro de relatos Adúlteras. En otra obra, Crimen imperfecto, recogida en la colección Cuatro obras políticamente incorrectas, esta misma autora presenta el monólogo de una mujer que se justifica a sí misma, torturándose, porque salió corriendo de casa con sus dos hijas y no despertó a su marido cuando en mitad de la noche la avisaron de que había un escape de gas y debían abandonar el edificio de inmediato. Tuvo varias oportunidades de salvarle y no lo hizo, acogiéndose a una excusa diferente cada vez, todas triviales. Su estado de nerviosismo la lleva a ser tratada por los psicólogos, que creen que no acepta la realidad, pero lo cierto es que la muerte de él ha sido toda una liberación para ella. 
y aun así se siente la víctima de la situación; con la amante que, cansada de serlo, llama a la esposa cornuda para que descubra a su marido con ella en la habitación del hotel donde se encuentran; con la que acude a un intercambio de pareja anónimo mientras su marido se queda en casa con los niños para que ella haga un recado; con la que fue casada sin amor, empujada por sus padres, y acaba siendo asesinada cuando su marido descubre que le es infiel; y otros ejemplos que presentan un variado muestrario de situaciones.

Estas protagonistas representan mujeres de edades, condiciones sociales e intereses personales diferentes, pero que comparten el mismo deseo de alcanzar unos derechos irrenunciables: la independencia económica, el desarrollo profesional y la libertad de movimiento y pensamiento. Su autorrealización personal está vinculada, según la propia autora, con una interacción sobre su entorno cargada de elementos ideológicos progresistas, que tiene como finalidad la revisión de los tradicionales modelos patriarcales y el deseo de derribarlos. Desde esa concepción de la mujer, y del papel de la misma en la sociedad y en el teatro, estas protagonistas son definidas por Juana Escabias como «malas», entendiendo por tal el ser transgresoras, a veces mujeres defensivas, incluso agresivas si es necesario, como respuesta a la hostilidad de un entorno en el que siguen siendo el «segundo sexo» (Escabias 2014, 219-228) ${ }^{12}$.

Si por un lado se presenta la evolución del paradigma femenino en su aspecto moral, por otro, a través de tres generaciones, Juana Escabias en Interiores (obra estrenada en 2008) muestra la contraposición entre modelos de mujer vanguardista y otros caducos, resaltando la repetición de ciertos esquemas emocionales. En Interiores el conflicto se plantea en tres actos divididos en varias secuencias. Los personajes son tres mujeres (Carla -madre-, María -su hija- y Carla -hija de María-) y tres hombres (Fernando -ex marido de María-, Miguel -marido de la joven Carla-y Santiago -padre de Miguel-). El acto primero nos sitúa en la década de mil novecientos sesenta, y en él vemos a Carla, nacida en los años cuarenta y modelo de buena mujer según los cánones de esa época, recién abandonada por su marido y con una hija de once años, María. Carla es víctima de una educación que le ha enseñado a tener miedo a la independencia y que la ha preparado para el matrimonio y, dentro de él, para que su marido e hija alcancen una autorrealización que ella nunca logrará:

Yo tenía preparada la maleta, escondida debajo de la cama, la tomé y salí a la calle, hacia el autobús de línea. Temblaba de expectación, iba a conocer el mundo, sería libre. No subí al autocar, me quedé en la esquina, observando

12. Para un acercamiento previo a la lectura de los sketches que configuran Nueve mujeres infieles, ver la reseña a la obra de Teruel Martínez. 
la parada. Sentí miedo. ¿Sería capaz de administrar mi propia vida? [...] Durante un tiempo dejé de tener sueños, nadie se percató. (Pausa). Cuando papá enfermó vinimos a vivir a la ciudad. Era maravilloso, coches, tranvías, riadas de gente, ruidos, tiendas... Yo ya tenía veinticuatro años. Me gustaba ir al trabajo, era el único momento en que podía conversar con otros seres humanos sin tener que preocuparme de que alguna amenaza cayera sobre mi honra. Era la dependienta más eficiente de todas, luego regresaba a casa y la vida continuaba siendo una prisión. [...] Creí que casándome escaparía de aquella falta de movimiento, de ese letargo que devoraba mis días. A veces pienso que mi vida no ha sido más que un muro frente a mí. (53-54)

Tras su separación, aparece un antiguo pretendiente con quien puede empezar una nueva vida, pero el rechazo de María, que no quiere compartir a su madre con nadie, hace que se aleje de él. En el mismo acto, en un salto temporal, años más tarde y con María adulta, la relación entre ambas es conflictiva, y la hija hará su vida sin agradecer a Carla su total entrega durante tantos años, «ejemplificando lo que la vida depara como pago a quienes sacrifican su felicidad por complacer a los demás»(Escabias 2014, 224).

No me trates como a una niña, tengo treinta y un años. [...] Esta mañana he alquilado un apartamento, mamá. Me marcho de casa. Necesito hacer mi vida, tienes que comprenderlo. [...] Compórtate como una adulta. Baja a la realidad. (Pausa). Probablemente me case en el verano. Antonio y yo lo hemos planificado todo en Nueva York. Ya conocerás a Antonio, te lo presentaré mañana mismo. [...] Hemos decidido que viviremos solos. Tú te vales por ti misma, cocinas, te desenvuelves... ¡Eres independiente! [...] No me mires con esa cara, si no te casaste con Eduardo fue porque no querías.(62)

Madre e hija componen una dualidad enfrentada de forma irremediable. El personaje de María se contrapone al de su madre, reclamando su proyección personal como derecho que cree le corresponde por nacimiento y anteponiendo su vida pública y profesional a las obligaciones familiares.

El acto segundo transcurre en la década de mil novecientos noventa. Aquí María es una mujer que amaba a su marido de una forma dependiente y posesiva, ahora separada de él, con una hija adolescente y una mala relación con su ex marido, y que chatea con hombres a través de la red para llenar su soledad. A lo largo del acto también se irán sucediendo los saltos temporales, a través de los cuales se mostrará la relación conflictiva entre madre e hija, y entre esta y su padre.

El acto tercero transcurre ya en el siglo XXI. La joven Carla acaba de ser madre. Aquí la voz protagonista es la de su pareja, Miguel, que con veintiocho años y un bebé recién salido del hospital, proyecta en su hijo la relación que él ha tenido con su padre. El progresista Miguel se niega a que su hijo conozca a Santiago, su abuelo paterno, porque, tras muchos años de matrimonio, este ha 
abandonado a su mujer por otro hombre. Santiago aparece e intenta explicar a su hijo cómo sacrificó su vida por no defraudar a su familia y cómo luego, por sus hijos y por respeto a su esposa, que sabía toda la verdad, necesitó vivir guardando las apariencias. Miguel le asegura que su rechazo se debe a que haya vivido una mentira toda su vida y no a su homosexualidad, pero un comentario irónico de Santiago sobre su homosexualidad y el bebé provoca la angustia de Miguel, que cierra la obra preguntando entre sollozos «No me engañes, dímelo, ¿también será maricón?» (85).

SANTIAGO.- (Observa a su nieto). Este niño está mirándome con complicidad. Parece que se alegra de que su abuelo sea ma-ri-ca. (Estupor de Miguel, que se asoma al cochecito para examinar a su hijo). Compruébalo por ti mismo, está haciéndome guiños.

Miguel.-(Observa al bebé. Solloza). ¿Crees que será maricón?

SANTIAGO.- No te lo tomes en serio, hijo mío, ha sido una chiquillada por mi parte.

MigueL.- Míralo bien. Sé sincero. Tú entiendes de esas cosas. ¿Tiene ojos de maricón?

SANTIAGO.- (Iniciando su salida de escena). Solo era una broma, vamos, tranquilízate.

Miguel.- (Persigue a su padre, que huye). Vamos, dime la verdad. ¿Crees que será maricón? Míralo bien. (84-85)

Como en Ser un hombre, la obra de Alejandro Butrón, pero también como en las otras donde la figura del varón aparece en un plano de mayor igualdad entre ambos sexos, Juana Escabias ofrece aquí la visión de que, si bien socialmente se ha avanzado en el camino por la emancipación femenina y en el lugar que ocupa la mujer en la sociedad, sin embargo queda todavía mucho por hacer para cambiar los patrones masculinos, cuyo pensamiento social y, sobre todo, cuya evolución emocional, se mantienen en un estadio arcaico.

Vamos a referirnos, por último, a la transformación de las identidades de género a través de un argumento que trata sobre la superación del dolor provocado por el desamor y abordado sin prejuicios desde distintas formas de amar y desde la desestructuración del mito del amor romántico. Lo hace el dramaturgo Alfredo Sanzol en su comedia La respiración (2016), una metáfora del bienestar emocional que ofrece diferentes perspectivas del amor a través de seis personajes enamorados los unos de los otros. Esta obra, escrita como autoterapia a partir de la separación real del autor de su pareja, con la que tenía un hijo, habla del amor en diferentes edades, de una manera intergeneracional, y lo hace mediante el acercamiento a diferentes tipos de relaciones, todas ellas poco ortodoxas. La obra escenifica cómo Nagore, la protagonista divorciada hace un año y con una hija pequeña, se reinventa en su necesidad de recuperar 
la respiración calmada, y con ella la autoestima que perdió al separarse. Incapaz de asumir su nueva situación, al principio su respiración es siempre ansiosa y a menudo se desmaya (cita 1) hasta que logra aceptar su nueva realidad (cita 2):

(CITA 1) NAGORE.- [...] ese hueco, ese silencio en el que solo me oigo a mí misma con la respiración ansiosa, entrecortada, es el reflejo exacto de cómo me encuentro. Soy una especie de náufraga en mi propia cama.(18)

(CITA 2) NAGORE.- [...] Os quiero agradecer muchísimo todo lo que me habéis hecho disfrutar durante esta fantasía, y es perfecto que se acabe. Las cosas no pueden durar siempre, aunque algunas veces nos gustaría.(155)

El espacio en el que todo transcurre es la casa de Nagore, porque toda la historia es, en realidad, una fantasía imaginada por ella a partir de un consejo que le da su madre: la ficción es el mejor entrenamiento para la realidad. Los personajes son tres hombres y tres mujeres. Los masculinos son sensibles emocionalmente y tienen oficios relacionados con la salud (Andoni es profesor de yoga; Íñigo es fisioterapeuta, y Mikel es preparador físico), y los femeninos están liberados sexualmente y sus trabajos pertenecen al ámbito de la justicia (Maite es una jueza jubilada, Nagore es una abogada de familia y Leire está recién licenciada en derecho). En tono amable, el texto reflexiona sobre el carácter incierto, posesivo $\mathrm{y}$, muchas veces, también caprichoso del amor, y la necesidad de quienes han sufrido un desengaño o una ruptura amorosa de adaptarse a la nueva situación ${ }^{13}$ :

LEIRE.- ¿Cuál es el problema aquí? (Pausa). ¿Que nos queremos los tres? $¿$ Ese es el problema? ¿Que yo os quiero a vosotros tres y que vosotros tres me queréis a mí? ¿Que Maite os quiere a los tres y los tres queréis a Maite? ¿Ese es el problema? (122)

En esta obra se anulan los patrones de feminidad y de masculinidad (lo cual es ya un rasgo de la evolución de los modelos anteriores), pues el objetivo es explorar la construcción de la autoestima en torno al amor y reflexionar sobre las relaciones amorosas sin distinción de género o de sexo. Al igual que en las primeras obras a las que nos referimos arriba, protagonizadas por personajes homosexuales, La respiración ofrece un muestrario de emociones en el que los rasgos psicológicos de cada personaje y su percepción o sus necesidades afectivas dentro de las relaciones interpersonales nada tienen que ver con patrones sociales de género, sino que dependen de la identidad individual de cada uno.

Otras de las obras que hemos comentado, sin embargo, sí se centran en los modelos de feminidad y masculinidad vigentes. En aquellas que se construyen

13. Ver reflexiones del autor sobre el proceso de creación y el significado de la obra en varias entrevistas en prensa con referencia en la bibliografía final. 
en torno al rol de la mujer madre o de la mujer trabajadora, se perciben los cambios de ambos paradigmas en el siglo XXI, dejando constancia a la vez del camino que todavía queda por recorrer. Respecto al rol masculino y sus normas de conducta social, se incide en que todavía parecen requerir importantes esfuerzos para su evolución.

En conclusión, el teatro lleva a escena personajes y argumentos con los que busca ofrecer un nuevo marco conceptual donde puede ser explorado lo femenino y lo masculino en su condición histórico-cultural. En las obras aludidas, los autores presentan a personajes, la mayoría de ellos héroes y heroínas vanguardistas; otros, por el contrario, antagonistas de los nuevos modelos y paradigmas, que actúan como espejos de la realidad que pretenden transformar para lograr, a través de la contraposición, que su mensaje cale en el receptor. En cierto modo, todas esas obras realizan pequeños análisis y su estudio comparado permite obtener un diagnóstico certero de las preocupaciones e inquietudes vitales y sociales latentes en la sociedad de principios del siglo XXI.

\section{REFERENCIAS BIBLIOGRÁFICAS}

AA.VV. El tamaño no importa (18). Textos breves de aquí y de ahora. Madrid: Asociación de Autores de Teatro, 2011.

Bravo, Julio. "Alfredo Sanzol estrena en La Abadía La respiración, una comedia romántica terapéutica».ABC Cultura, 14 de enero de 2016. <http://www.abc. es/cultura/teatros/abci-alfredo-sanzol-estrena-abadia-respiracion-comedia-romantica-terapeutica-201601142044_noticia.html>, consultado el 20-10-2017.

Butrón, Alejandro. Ser un hombre, inédito. Documento recibido del propio autor a través de <http://www.contextoteatral.es/serunhombre.html>, consultado el 20-10-2017. Año de escritura: 2017.

Corral, Javier. Mis padres no lo saben. Montaje teatral.<http://mispadresnolosaben. blogspot.com.es/>, consultado el 20-10-2017.

Escabias, Juana. Interiores. Madrid: Huerga y Fierro editores, 2010.

Escabias, Juana. Nueve mujeres infieles. Madrid: Ediciones Irreverentes, 2011.

Escabias, Juana. «Malas y más que malas, por supuesto: Breve alegato sobre la necesidad de ir contra corriente». Malas. Eds. Margarita Almela, María García Lorenzo y Helena Guzmán. Madrid: UNED, 2014. 219-228.

Escabias, Juana. Cuatro obras políticamente incorrectas. Madrid: Esperpento ediciones, 2015.

G. Almansa, Pilar. Cama, inédito. Documento recibido de la propia autora a través de < http://www.contextoteatral.es/pilargalmansa.html>, consultado el 20-102017. Año de escritura: 2015. 
Hernández, Maykol. Desmontando a don Juan, inédito. Documento recibido del propio autor a través de <http://www.contextoteatral.es/desmontandoadonjuan.html>, consultado el 20-10-2017. Año de escritura: 2011.

Matteis, Carlos de. La Vida es Bell@. Montaje teatral. <http://www.alternativateatral. com/persona39338-carlos-de-matteis>, consultado el 20-10-2017.

Matteis, Carlos de. Cállate y bésame. Montaje teatral. <http://www.alternativateatral.com/persona39338-carlos-de-matteis>, consultado el 20-10-2017.

Ortiz, Lourdes. «Algo se consigue». Malas. Eds. Margarita Almela, María García Lorenzo y Helena Guzmán. Madrid: UNED, 2014, 485-494.

Resino de Ron, Carmen. «Buenas y malas». Malas. Eds. Margarita Almela, María García Lorenzo y Helena Guzmán. Madrid: UNED, 2014, 495-498.

Rodríguez, Marce y Mariola Cubells. Mis padres no lo saben. Barcelona: Plaza\&Janés, 2009.

Sanzol, Alfredo. La respiración. Madrid: Ediciones Antígona, 2016.

Sarriás Forner, Mercedes. Hazme una perdida, inédito. Documento recibido de la propia autora a través de <http://www.contextoteatral.es/hazmeunaperdida. html>, consultado el 2-06-2017. Año de escritura: 2014.

Teruel Martínez, Susana. «Mujeres infieles». El Kiosko teatral. De aquí y de ahora. Teatro Español Contemporáneo, n. ${ }^{\circ}$ VI. <http://www.aat.es/elkioscoteatral/ leer-teatro/leer-teatro-6-sumario/no-6-de-aqui-y-de-ahora-1-6-teatro-espanolcontemporaneo/>, s.a., consultado el 2-06-2017.

Valle, Emilio de, Jorge Muñoz, Marta Belenguer, Rosa Manteiga, Carolina Solas y María Vázquez. Femenino singular. Montaje teatral. <http://joomlal.inconstantes.com/index.php?option=com_content\&view=article $\&$ id $=51 \&$ Itemid=8>, consultado el 20-10-2017.

Vicente, Álvaro. «La Respiración de Alfredo Sánzol. Entrevista».Godot 60, añoVII (2016): 22-24. <http://www.escenagodot.com/entrevistas/80-La-Respiracinde-Alfredo-Sanzol>, consultado el 2-06-2017.

Vila, José-Miguel. «La respiración y la adversidad. Reseña». Diariocrítico.com, 28 de enero de 2016. <https://www.diariocritico.com/la-respiracion-alfredo-sanzol>, consultado el 2-06-2017. 